\title{
Choice of Take-Back Models for the End-of-Life Electromechanical Products Based on Fuzzy Analytic Network Process Method
}

\author{
Liu Wenjie ${ }^{1}$, Liu Xiaojun ${ }^{2}$, Wang Yanling ${ }^{3}$ \\ ${ }^{1}$ College of Economics and Management, Nanjing University of Aeronautics and Astronautics, Nanjing 211106, China \\ ${ }^{2}$ Marketing and Sales Committee, China Eastern Airlines Corporation Limited, Shanghai 201202, China
}

\begin{abstract}
When choosing take-back models for End-of-Life electromechanical products, we shall have to face a complex situation. It is necessary for us to consider the network relationships with interaction and feedback between different types of evaluation indices, such as economic index, technical index, social index, etc, and to deal with the problem of strong fuzziness while experts judging the relative importance of different indices. In order to solve the above problems, an evaluation index system for take-back model choosing is established firstly, which is comprised of the indices of economic performance, social \& ecological benefits, technical performance and enterprise development strategy. It fully reflects the network relationship of different evaluation indices. Secondly, a Fuzzy Analytic Network Process model is put forwarded to implement the choice of take-back models, using the fuzzy comprehensive evaluation to overcome the fuzziness of the expert evaluation, adopting Analytic Network Process to analyze the network relationship between the indices. Finally, a take-back case for the used car engine is taken to verify the feasibility and validity of the model.
\end{abstract}

Keywords: Fuzzy Analytic Network Process; End-of-Life Electromechanical Products; Super matrix; Take-back Models

\section{Introduction}

In the traditional development model, products go through the stages of design $\rightarrow$ manufacture $\rightarrow$ use $\rightarrow$ discard, forming a development pattern that is from cradle to grave, its malpractice is a serious global resource shortage and environmental pollution. According to the statistics of the UN Environment Program, more than $70 \%$ of global pollutants come from electromechanical products manufacturing industry, which is the largest source of environmental pollution in the world. The situation in China is not optimistic. According to the National Bureau of Statistics, China annually creates 4, 000, 000 units of scrap cars and 150,000 units of engineering machines abandon 4, 000,000 units of discarded refrigerators and 6,000,000 units of washing machines. Recycling of the end-of-life electromechanical products has the benefit of saving resources and significant impact on reducing energy consumption and pollutant emissions. Therefore, how to efficiently carry out recycling of used electromechanical products becomes the focus of governments.

In recent years, many scholars have pay more attention on the choice of different take-back models in used product recycling, and carried out relevant researches from the qualitative and quantitative aspects. In qualitative research, Spicer, etc. (2004) ${ }^{[1]}$, Xu Zhiduan, etc.(2005) ${ }^{[2]}$, Luo Wei (2009) ${ }^{[3]}$ In a perspective of extending the responsibility of manufacturers, they gave a qualitative analysis of three kinds of product take-back models, manufacturers recycling, manufacturers joint recycling and third-party recycling. They pointed out that third-party product take-back model is the best of all. Zhang Heng (2007) ${ }^{[4]}$, Yan Xinxin (2008) ${ }^{[5]}$ discussed the advantages and disadvantages of different product tack-back models qualitatively, focusing on analysis of the key factor that impacts the selection of tack-back model.In quantitative research, Govindan, etc. (2002) ${ }^{[6]}$ used the analytic structure of the model to analyze the third-party recyclers selection; Savaskan, etc. $(2004)^{[7]}$, Yao Weixin (2006) ${ }^{[8]}$, Wei Jie (2005) ${ }^{[9]}$, Wang Xuan (2009) ${ }^{[10]}$ constructed a profit function model for participating companies under the three recycling models--manufacturers recycling retailers recycling and third-party recycling. They selected the best model based on the principle of profit maximization; Gong Yande (2010) ${ }^{[11]}$ used game analysis method to construct a closed-loop supply chain model within two product tack-back models of retailers recycling and manufacturers recycling, focusing on analysis of critical condition of manufacturer while using recycled outsource; Ren Mingming (2009) ${ }^{[12]}$ used fuzzy comprehensive evaluation method to study the selection problem of product tack-back models.

When selecting the take-back models for used electromechanical products, it involves economic, technical, society, management and other qualitative and quantitative evaluation index, which have a network structure relationship of mutual influence and interaction. In the meanwhile, there is a strong fuzziness while experts judging their relative importance. At present, domestic and foreign scholars have made a more extensive research, providing for this study useful references. But the defects are as following: (1) literatures on qualitative research [1-5] failed to consider the impact of quantitative evaluation on the take-back models selection; (2) literatures on quantitative research [6-11] only considered the profits of recycling business, while ignoring the evaluation on social, technical and other important performance. Although the literature [12] established evaluation model that contains the above three types of fuzzy comprehensive evaluation index, but not yet analyze and solve evaluation relationship that exists between the network structures. Therefore, this article uses Fuzzy Network Analysis Process to construct selection model of electromechanical products take-back models. The using fuzzy comprehensive evaluation overcomes the fuzziness of 


\section{International Journal of Science and Research (IJSR) \\ ISSN (Online): 2319-7064}

Index Copernicus Value (2013): 6.14 | Impact Factor (2014): 5.611

expert evaluation and using Analytic Network Process to evaluate the network structure relationship of different index.This study can provide scientific reference for enterprises in decision-making on selection of take-back models for used products.

\section{Emphasis and difficulties in designing evaluation system for selecting take-back models}

\subsection{Emphasis in designing evaluation system}

The key point of designing an evaluation system is to build a scientific evaluation index system for selecting take-back models of end-of-life electromechanical products. It needs to focus on the following requirements: First, to fully reflect the principal requests of varied participating subjects. The recycling of electromechanical product involves in customers (waste product providers), recycling companies (manufacturers, manufacturers of a commonwealth or a trusted third party recycling companies), government agencies (recycling supporters and guide) and other participating subjects, evaluation index system needs to reflect their different recycling requests ; Second, try to include the key evaluation indexes that truly impact selection of take-back models. In addition to focus on evaluation index of economic performance, the evaluation index system should also be designed to include product type, consumer acceptance and involvement, the type of business strategy and ability to control recovery and other key evaluation index that directly affect the take-back models selection. Last, to reflect the internal network structure relation of interdependence and feedback between the evaluation indexes.

\subsection{Difficulties in designing evaluation system}

The evaluation process faces two major problems: First, the evaluation indexes present a network structure relation of interdependence and mutual influence (Figure1) rather than a simple hierarchical one; Second, expert evaluation has a fuzzy uncertainty. While judging the relative importance of two evaluation indexes, influenced by the subjective judgment and personal preferences, the judgment of experts typically exhibit a strong fuzzy uncertainty that can not directly use a common expression of discrete scale (e.g. 0-1 three scaling, 0.1-0.9 five marks and 0.1 to 0.9 nine degrees). These questions make it the key point of evaluation system that how to determine the weights of evaluation indexes, which shall be settled with our intends to adopt fuzzy analytic network process FANP.

\section{Design Evaluation Index System for Choosing Take-Back Models}

\subsection{Design evaluation index system}

The study take evaluation index systems studied in domestic and foreign research for reference, and investigate the National Development and Reform Central Information Secretary, Energy Division of Ministry of Industry and Information Technology and other government departments, remanufacturing business executives and consumer groups, condense out the evaluation index system for selecting take-back models of the end-of-life electromechanical product as shown in Figure 1.

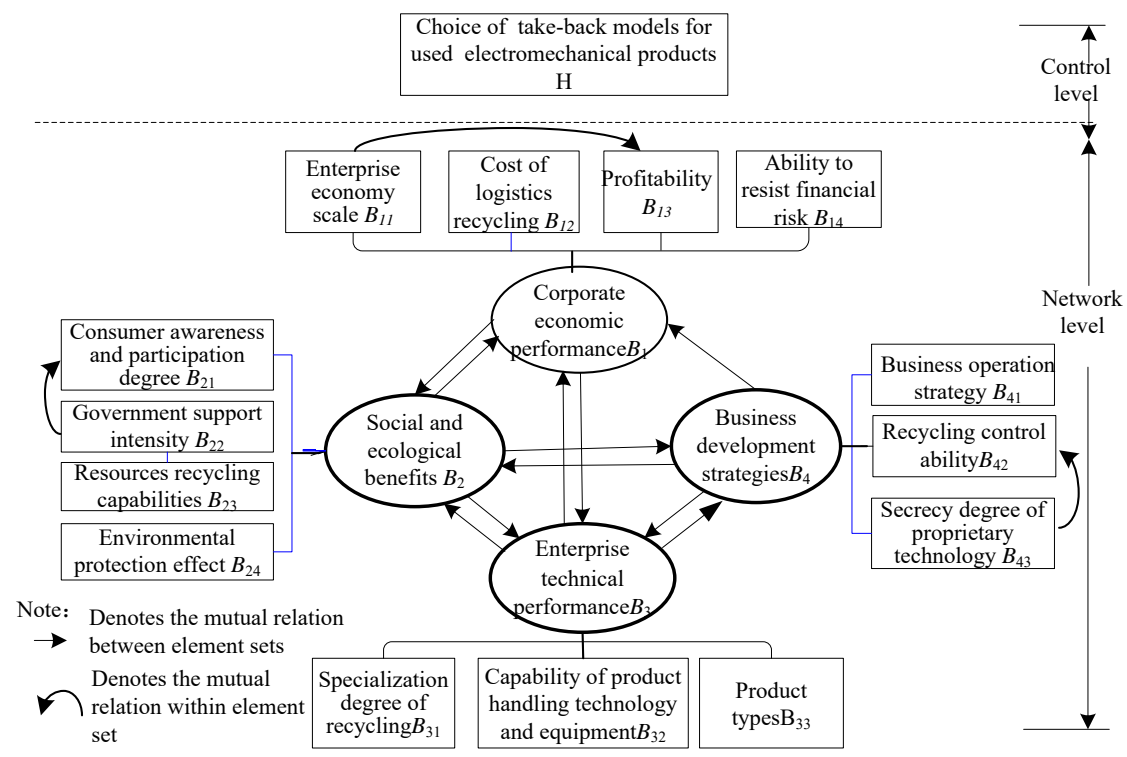

Figure 1: Evaluation index system of take-back models for waste electromechanical products

The index system is divided into control layer and network layer, the control layer mainly includes evaluation objectives(i.e. evaluation result of selecting tack-back models) without evaluation criteria; the network layer is designed as a evaluation index layer, which includes 4 first-level evaluation index factor set of corporate economic performance $B_{1}$, social and ecological benefits $B_{2}$, enterprise technical performance $B_{3}$ and business development strategies $B_{4}$, and are consist of 14 second-level evaluation indexes. 


\section{International Journal of Science and Research (IJSR) \\ ISSN (Online): 2319-7064}

Index Copernicus Value (2013): 6.14 | Impact Factor (2014): 5.611

\subsection{Main Features of evaluation index system}

The evaluation index system above has features as followings: First, it fully considers the impact of consumers on product take-back models. Recognition and participation degree of cconsumerss directly relates to the number of recycling products, thus influences the selection of tack-back models. For example, active participation of consumers will lead to increase in the recycling number of products, based on which the manufacturer recycling model would be considered. In this paper, evaluation index"consumer awareness and participation degree $B_{21}$ "is included in the index" social and ecological benefit $B_{2}$ "; Second, it adds the evaluation index factor set of "business development strategies $B_{4}$ ". Development strategies of eenterprises directly affect selection of product take-back models, for instance, companies may use technology leading, development speed priority, operation safety and other business strategies, where technology leading strategy focus on taking the human, financial, supplies and other limited resources into advanced remanufacturing technology research and development, these companies tend to choose third-party take-back model, while companies that apply operation safety strategy are more likely to choose the manufacturer take-back model. Meanwhile, as companies have different requirements on "recycling control ability" and "confidentiality of products proprietary technology", the models are also distinguished. Companies with higher requirements (which hope to strictly control the product recycling process and to prevent leakage of product technology)are more tend to choose the manufacturer take-back model. Third, it reflects the internal network structure relation between the evaluation indexes.In the evaluation index system, there is an interdependent network structure relation within a same set or between different ones. For instance, in the same factor set, while "government support intensity $B_{22}$ " increases, "consumer awareness and participation degree $B_{21}$ "effectively get improved, and"enterprise economy scale $B_{11} "$ expanses, "profitability $B_{13}$ " effectively get enhanced; Between different index sets, while "consumer awareness and participation degree $B_{21} "$ is relatively low, take-back products will be not enough to form a certain scale effect, thus the factor" cost of logistics recycling $B_{12}$ ", included in" enterprise economic performance $B_{1}$ ", is bound to increase. While "capability of product handling technology and equipment level $B_{32}$ " that included in "enterprise technology performance $B_{3} \quad$ "improves, "resources recycling capabilities $B_{23}$ ", which included in the" social and ecological benefits $B_{2}$ ", increases accordingly.At the same time, the promotion of" specialization degree of recycling $B_{31}$ "will lead to a reduction of "cost of logistics recycling $B_{12}$ " that included in" enterprise economic performance $B_{1}$ ".However, as the "business operation strategy $B_{41}$ "included in" enterprise development strategy $B_{4} "$ adopting technology leading strategy, "capability of product handling technology and equipment level $B_{32} \quad$ "contained in "enterprise

technology performance $B_{3}$ "is getting effectively enhanced.

\section{Construct the Fuzzy Network Analysis process Model}

Construct a F-ANP model to solve the selection problem of end-of-life electromechanical product take-back models, the modeling process are as followings:

Step1: Select an object set $O$ to study. Use $O=\left\{O^{1}, O^{2}, \cdots, O^{m}, \cdots, O^{M-1}, O^{M}\right\}$ to represent $\mathrm{M}$ kinds of optional take-back models, $O^{m}$ denotes the $m$ th product take-back model, $m=1,2, \ldots, M$.

Step2: Design the evaluation index system (Figure1)and define the evaluation factor set. The evaluation index system is denoted by $B=\left\{B_{1}, B_{2}, B_{3}, B_{4}\right\}$, set $i$ is denoted by $B_{i}=\left\{B_{i 1}, B_{i 2}, \ldots, B_{i p}, \ldots, B_{i i_{i}}\right\} . B_{i p}$ denotes the $p$ th index in the evaluation factor set $i, i=1,2,3,4, \quad p=1,2, \ldots, n_{i}, \quad n_{i}$ denotes the number of evaluation indexes in set $B_{i}$.

Step3: Build expert evaluation remark set $V$.The expert evaluation remark set is denoted by $V=\left\{V_{1}, V_{2}, \cdots, V_{k}, \cdots, V_{K-1}, V_{K}\right\}$, where the $V_{k}$ denotes the $k$ th, $k=1,2, \ldots, K$.In order to collect the scores of varied product take-back models, we apply hundred-mark system to represent varied remark scores, thus forming the vector of expert remark scores $R=\left(r_{1}, r_{2}, \cdots, r_{k}, \cdots, r_{K-1}, r_{K}\right)$.

Step4:To obtain the fuzzy relation matrix $S$, that of evaluation index set $B$ relative to expert remark set $V$, under different product take-back models. In regard to $M$ types of take-back models, obtain the fuzzy relation matrix $S=\left(S^{1}, S^{2}, \cdots, S^{m}, \cdots, S^{M}\right)$, according to expert remarks. Where $S^{m}=\left(S V_{1}^{m}, S V_{2}^{m}, S V_{3}^{m}, S V_{4}^{m}\right)^{T}$ denotes the fuzzy relation matrix under the $m$ th take-back model, and $S V_{i}^{m}$ denotes the fuzzy relation matrix that of evaluation index set $B_{i}$ compares to expert remark set $V, i=1,2,3,4$.

$$
S V_{i}^{m}=\left[\begin{array}{ccccccc}
s_{i 1,1}^{m} & s_{i 1,2}^{m} & \ldots & s_{i 1, k}^{m} & \ldots & s_{i 1, K-1}^{m} & s_{i 1, K}^{m} \\
s_{i 2,1}^{m} & s_{i 2,2}^{m} & \ldots & s_{i 2, k}^{m} & \ldots & s_{i 2, K-2}^{m} & s_{i 2, K}^{m} \\
\vdots & \vdots & \vdots & \vdots & \vdots & \vdots & \vdots \\
s_{i p, 1}^{m} & s_{i p, 2}^{m} & \ldots & s_{i p, k}^{m} & \ldots & s_{i p, K-1}^{m} & s_{i p, K}^{m} \\
\vdots & \vdots & \vdots & \vdots & \vdots & \vdots & \vdots \\
s_{i n_{i}-1,1}^{m} & s_{i n_{i}-1,2}^{m} & \ldots & s_{i n_{i}-1, k}^{m} & \ldots & s_{i n_{i}-1, K-1}^{m} & s_{i n_{i}-1, K}^{m} \\
s_{i n_{i}, 1}^{m} & s_{i n_{i}, 2}^{m} & \ldots & s_{i n_{i}, k}^{m} & \ldots & s_{i n_{i}, K-1}^{m} & s_{i n_{i}, K}^{m}
\end{array}\right]
$$

Element $s_{i p, k}^{m}$ of the fuzzy relation matrix $S V_{i}^{m}$ denotes the subjection degree of evaluation index $B_{i p}$ relative to expert remark $V_{k}, \quad i=1,2,3,4, \quad p=1,2, \ldots, n_{i}, \quad k=1,2, \ldots, K$.

Step5: To obtain the weight of each evaluation index $W$ with Fuzzy-Analytic Network Process FANP.FANP is an extension of ANP in the issue of uncertainty and ambiguity,

the basic idea is: First, construct weight super-matrix $\tilde{W}$ for second-level evaluation indexes(detailed in follow-up 


\section{International Journal of Science and Research (IJSR) \\ ISSN (Online): 2319-7064}

Index Copernicus Value (2013): 6.14 | Impact Factor (2014): 5.611

(1)construct weight super-matrix for second-level evaluation indexes).There is a fuzzy uncertainty while experts judging the relative $\tilde{W}$ importance of two second-level indexes, for this situation, use triangular fuzzy numbers to truly reflect its fuzzy uncertainty, construct indirect dominance degree judging matrix of triangular fuzzy numbers that come from different experts, thus effectively building weight super-matrix $\tilde{W}$ for second-level evaluation indexes; second, construct fuzzy weight super-matrix $A$ for first-level evaluation index set by the same way we constructing super-matrix $\tilde{W}$; third, combine the two weight super-matrix to construct the fuzzy weighted super-matrix for evaluation indexes, $\bar{W}=A \bullet \tilde{W}$; last, Super-matrix Analysis contained in Analytic Network Process ANP has an advantage of exploring the interdependencies between evaluation indexes, take this advantage to analysis fuzzy weighted super-matrix $\bar{W}$ and obtain the weight vector $W$ for evaluation indexes:

(1) Construct super-matrix $\tilde{W}$ for second-level evaluation indexes

$$
\tilde{W}=\left[\begin{array}{llll}
w_{11} & w_{12} & w_{13} & w_{14} \\
w_{21} & w_{22} & w_{23} & w_{24} \\
w_{31} & w_{32} & w_{33} & w_{34} \\
w_{41} & w_{42} & w_{43} & w_{44}
\end{array} \mid\right.
$$

The sub-block $w_{i j}(i, j=1,2,3,4)$ in $\tilde{W}$ indicates the weight matrix of influence degree between evaluation index set $B_{i}$ and $B_{j}$, it reflects the mutual-feedback network structure relation between evaluation indexes:

$$
\begin{aligned}
& w_{i j}=\left[w^{(j 1)}, w^{(j 2)}, \ldots, w^{(j q)}, \ldots, w^{\left(j n_{j}\right)}\right] \\
& =\left[\begin{array}{cccccc}
w_{i 1}^{(j 1)} & w_{i 1}^{(j 2)} & \ldots & w_{i 1}^{(j q)} & \ldots & w_{i 1}^{\left(j n_{j}\right)} \\
w_{i 2}^{(j 1)} & w_{i 2}^{(j 2)} & \ldots & w_{i 2}^{(j q)} & \ldots & w_{i 2}^{\left(j n_{j}\right)} \\
\vdots & \vdots & \vdots & \vdots & \ldots & \vdots \\
w_{i p}^{(j 1)} & w_{i p}^{(j 2)} & \ldots & w_{i p}^{(j q)} & \ldots & w_{i p}^{\left(j n_{j}\right)} \\
\vdots & \vdots & \vdots & \vdots & \vdots & \vdots \\
w_{i n_{i}}^{(j 1)} & w_{i n_{i}}^{(j 2)} & \ldots & w_{i n_{i}}^{(j q)} & \ldots & w_{i n_{i}}^{\left(j n_{j}\right)}
\end{array}\right]
\end{aligned}
$$

Where column vector $w^{(j q)}=\left(w_{i 1}^{(j q)}, w_{i 2}^{(j q)}, \ldots, w_{i p}^{(j q)}, \ldots, w_{i n_{i}}^{(j q)}\right)^{T}$ denotes the sorted vector of impact, that of each evaluation index $B_{i p}$ in evaluation index set $B_{i}$ on evaluation index $B_{j q}$ in set $B_{j}$, where $p=1,2, \ldots, n_{i}, q=1,2,3, \ldots, n_{j}$.The column vector is generated :

1) Denote indirect dominance of experts by triangular fuzzy numbers, construct judgment matrix $Z^{h}$ for expert evaluation triangular fuzzy numbers

Take index $B_{j q}$ as a criteria, compare the indirect dominance of each index $B_{i p}$ included in set $B_{i}$ according to $B_{j q}$ its relative influence on index $B_{j p}$.Considering of the uncertainty of expert evaluation, triangular fuzzy numbers are used to denote the indirect dominance of two evaluation indexes within $B_{i}$. Suppose there are $H$ experts involved in indirect dominance evaluation, then $H$ indirect dominance judgment matrix $Z^{h}$ for triangular fuzzy numbers shall be formed as shown in Table 1.

The evaluation matrix is denoted by $Z^{h}=\left(z_{e f}^{h}\right)_{n_{i} \times n_{i}}, \quad h=1,2, \ldots H$, $e, f=1,2, \ldots n_{i}, \quad z_{e f}^{h}=\left(l_{e f}^{h}, m_{e f}^{h}, u_{e f}^{h}\right)$ is a triangular fuzzy number that denotes the indirect dominance of expert evaluation, the parameters $l_{e f}^{h}, m_{e f}^{h}, u_{e f}^{h}$, respectively, denotes the most pessimistic value, the largest possible value, and the most optimistic value of indirect dominance that of index $B_{i e}$ relative to $B_{i f}$.

Table 1: Indirect dominance judging matrix $Z^{h}$ benchmarked

\begin{tabular}{c|cccccc}
\multicolumn{10}{c}{ by $B_{j q}$} \\
\hline$B_{j q}$ & $B_{i 1}$ & $B_{i 2}$ & $\ldots$ & $B_{i f}$ & $\ldots$ & $B_{i n_{i}}$ \\
\hline$B_{i 1}$ & $z_{11}^{h}$ & $z_{12}^{h}$ & $\ldots$ & $z_{1 f}^{h}$ & $\ldots$ & $z_{1 n_{i}}^{h}$ \\
$B_{i 2}$ & $z_{21}^{h}$ & $z_{22}^{h}$ & $\ldots$ & $z_{2 f}^{h}$ & $\ldots$ & $z_{2 n_{i}}^{h}$ \\
$\vdots$ & $\vdots$ & $\vdots$ & $\vdots$ & $\vdots$ & $\vdots$ & $\vdots$ \\
$B_{i e}$ & $z_{e 1}^{h}$ & $z_{e 2}^{h}$ & $\ldots$ & $z_{e f}^{h}$ & $\ldots$ & $z_{e n_{i}}^{h}$ \\
$\vdots$ & $\vdots$ & $\vdots$ & $\vdots$ & $\vdots$ & $\vdots$ & $\vdots$ \\
$B_{i n_{i}}$ & $z_{n_{i} 1}^{h}$ & $z_{n_{i} 2}^{h}$ & $\ldots$ & $z_{n_{i} f}^{h}$ & $\ldots$ & $z_{n_{i} n_{i}}^{h}$ \\
\hline
\end{tabular}

2) Mass judgment matrixes of triangular fuzzy numbers $Z_{h}$ to form a single judgment matrix $Z$, calculate the fuzzy comprehensive evaluation value $a_{e}$ of second-level evaluation indexes.

Mass the preference information of triangular fuzzy judging matrix- $\mathrm{H}$, in number-with the methods adopted in literature [14] to form a single triangular fuzzy judging matrix $Z=\left(z_{e f}\right)_{n_{i} \times n_{i}}$, and calculate the fuzzy comprehensive value $a_{e}$ of each second-level index, that is:

$$
\begin{aligned}
Z_{e f} & =\left(l_{e f}, m_{e f}, u_{e f}\right)=(1 / h) \leftarrow\left(z_{e f}^{1} \bullet z_{e f}^{2} \ldots z_{e f}^{h} \ldots \bullet z_{e f}^{H}\right) \\
& =\left(\left(\sum_{h=1}^{H} l_{e f}^{h}\right) / h,\left(\sum_{h=1}^{H} m_{e f}^{h}\right) / h,\left(\sum_{h=1}^{H} u_{e f}^{h}\right) / h\right)
\end{aligned}
$$

Where the mark $\bullet$ and $\leftarrow$ denotes addition and multiplication of triangular fuzzy numbers respectively, $e, f=1,2, \ldots n_{i}$

$$
\begin{aligned}
& a_{e}=\left(l_{e}, m_{e}, u_{e}\right)=\left(\sum_{f=1}^{n_{i}} l_{e f}, \sum_{f=1}^{n_{i}} m_{e f}, \sum_{f=1}^{n_{i}} u_{e f}\right) \leftarrow \\
& {\left[\sum_{e=1}^{n_{i}} \sum_{f=1}^{n_{i}} l_{e f}, \sum_{e=1}^{n_{i}} \sum_{f=1}^{n_{i}} m_{e f}, \sum_{e=1}^{n_{i}} \sum_{f=1}^{n_{i}} u_{e f}\right]^{-1}, e=1,2, \ldots n_{i}}
\end{aligned}
$$

3) Compute the expectation $E\left(a_{e}\right)$ of fuzzy comprehensive evaluation value $a_{e}$ and acquire the sorted vector of impact $w^{j q}$ through normalization process.

Compute the expectation $E\left(a_{e}\right)$ of fuzzy evaluation value $a_{e}$ for each second-level evaluation index, with analytic methods applied in literature [15][16], and acquire the sorted vector of impact $w^{j q}$ through normalization process.

$E\left(a_{e}\right)$ and $w^{j q}$ are calculated as:

$$
E\left(a_{e}\right)=\eta\left(l_{e}+m_{e}\right) / 2+(1-\eta)\left(m_{e}+u_{e}\right) / 2
$$

$e=1,2, \ldots n_{i} \quad \eta$ denotes the optimism-pessimism factor, $0 \leq \eta \leq 1$ (expert evaluation is neutral, if $\eta=0.5$;pessimistic, if $\eta>0.5$; and optimistic, if $\eta<0.5, \mathrm{n}$ depends on concrete situation.) 


\section{International Journal of Science and Research (IJSR) \\ ISSN (Online): 2319-7064}

Index Copernicus Value (2013): 6.14 | Impact Factor (2014): 5.611

$$
\begin{gathered}
w^{(j q)}=\left(w_{i 1}^{(j q)}, w_{i 2}^{(j q)}, w_{i 3}^{(j q)}, \ldots, w_{i i_{i}}^{(j q)}\right)^{T} \\
w_{i e}^{(j q)}=E\left(a_{e}\right) / \sum_{e=1}^{n_{i}} E\left(a_{e}\right), \quad e=1,2, \ldots n_{i}
\end{gathered}
$$

(2) Construct the fuzzy weight matrix of first-level evaluation index factor set, $A$

Given that the sub-block $w_{i j}(i, j=1,2,3,4)$ of second-level evaluation index weight super-matrix $\tilde{W}$ is column normalized, whereas $\tilde{W}$ is not, the relative importance of first-level evaluation index factor set shall be compared to obtain the fuzzy weight matrix $A$ of evaluation index factor set(the same way as obtaining second-level evaluation index weight matrix above.).

$$
A=\left[\begin{array}{llll}
a_{11} & a_{12} & a_{13} & a_{14} \\
a_{21} & a_{22} & a_{23} & a_{24} \\
a_{31} & a_{32} & a_{33} & a_{34} \\
a_{41} & a_{42} & a_{43} & a_{44}
\end{array} \mid\right.
$$

Where element $a_{i j}$ denotes relative weight of evaluation index factor set $B_{i}$ to $B_{j}, i, j=1,2,3,4$.

(3) Construct fuzzy weighted super-matrix $\bar{W}$, compute its limit stable vectors $W$ as the weight of each second-level evaluation index

$$
\bar{W}=A \bullet \tilde{W}=\left|\begin{array}{llll}
a_{11} w_{11} & a_{12} w_{12} & a_{13} w_{13} & a_{14} w_{14} \\
a_{21} w_{21} & a_{22} w_{22} & a_{23} w_{23} & a_{24} w_{24} \\
a_{31} w_{31} & a_{32} w_{32} & a_{33} w_{33} & a_{34} w_{34} \\
a_{41} w_{41} & a_{42} w_{42} & a_{43} w_{43} & a_{44} w_{44}
\end{array}\right|
$$

Stabilize the fuzzy weighted super-matrix $\bar{W}$, compute its stable limit vectors $W$ as the weight of each second-level evaluation index.

$$
\begin{gathered}
W=\lim _{k \rightarrow \infty}(\bar{W})^{k}=\left(W_{11}, W_{12}, \ldots, W_{1 n_{1}}, W_{21}, W_{12}, \ldots, W_{2 n_{2}}, W_{31},\right. \\
\left.W_{32}, \ldots, W_{3 n_{3}}, W_{41}, W_{42}, \ldots, W_{4 n_{4}}\right)
\end{gathered}
$$

Where element $W_{i p}$ in $W$ denotes the weight of second-level evaluation index $B_{i p}, i=1,2,3,4, \quad p=1,2, \ldots, n_{i} n_{i}$ denotes the number of index in evaluation index factor set $B_{i}$.

Step6: Apply fuzzy comprehensive evaluation model $M(\bullet,+)$ to calculate the final evaluation score of $\mathrm{M}$ types of end-of-life electromechanical product take-back models. Based on evaluation index weight $W$, fuzzy relation matrix $S$ and expert remark vectors $R$, use fuzzy comprehensive evaluation to calculate final evaluation scores of various take-back models $T=\left(T^{1}, T^{2}, \ldots, T^{m}, \ldots, T^{M-1}, T^{M}\right) \cdot T^{m}$ denotes the final score of the $m$ th take-back model, which is calculated by $T^{m}=W\left\lceil S^{m} \square R^{T}\right.$.

Step7: Choose the highest scoring take-back model in vector $T$ as the best choice of take-back models.

\section{Case Study}

\subsection{Selection of waste automobile engine recycling models}

It has been nearly two decades since the recycling and remanufacturing of waste automobile engine appeared in
China, Shanghai Volkswagen, China National Heavy Duty Trunk, Yuchai Group, Dongfeng Cummins and other Chinese major auto companies have carried out this business. The study take domestic waste automobile engine recycling models as example to analysis, the specific process is as followings:

Step1: Select an object set $O$ to study. Currently, there are mainly three kinds take-back models in waste automobile engine recycling, manufacturer recycling, dealer recycling and third-party organizations recycling, say, $M=3$. Therefore, object set $O=\left\{O^{1}, O^{2}, O^{3}\right\}$ is selected for research.

Step2: Design the evaluation index system as shown in Figure 1.The evaluation index system is denoted as $B=\left\{B_{1}, B_{2}, B_{3}, B_{4}\right\}$ (Detailed in preamble "2.Design evaluation index system for take-back models selection of the end-of-life electromechanical product " ), the structural relation of the evaluation index is shown in table1, $n_{1}=4$, $n_{2}=4, n_{3}=3, n_{4}=3$ respectively denotes the number of evaluation index for evaluation index factor set $B_{1}, B_{2} 、 B_{3}$ and $B_{4}$.

Step3: Build expert evaluation remark set $V$.Considering that experts have preference for 5 kinds of different remarks (that is, $K=5 \quad$, the remark set is settled as $V=\left\{V_{1}, V_{2}, V_{3}, V_{4}, V_{5}\right\}=\{$ excellent, well, fair, poor, bad $\}$, score vector of experts remark accordingly to be $R=(100,80,60,40,20)$.

Step4: To obtain the fuzzy relation matrix $S$, that of evaluation index set $B$ compares to expert remark $\operatorname{set} V$, under three different product take-back models.

To ensure the evaluation model scientific and rational, we carefully select 30 people, including remanufacturing business executives, remanufacturing industry experts from Combustion Engine Industry Association, scholars that is familiar with waste automobile engine recycling in universities, to make single factor evaluation on second-level evaluation indexes for 3 kinds of take-back models through questionnaires. Obtain the survey table by recycling and sorting, ascertain the relative fuzzy relation matrix $S=\left(S^{1}, S^{2}, S^{3}\right)$, that of $\operatorname{set} B$ compares to $\operatorname{set} V$, under different product take-back models.

Limited by article length, we merely give out the construction process of fuzzy relation matrix $S^{1}$ under manufacturer recycling model(fuzzy relation matrix $S^{2}$ and $S^{3}$ are built with the same process). The fuzzy relation matrix $S^{1}$ can be ascertained, according to the available experts evaluation survey statistics of second-level evaluation index, as shown in Table2. 


\section{International Journal of Science and Research (IJSR) \\ ISSN (Online): 2319-7064 \\ Index Copernicus Value (2013): 6.14 | Impact Factor (2014): 5.611}

Table 2: Experts evaluation survey table of second-level evaluation index under manufacturer recycling model

\begin{tabular}{|c|c|c|c|c|c|c|}
\hline \multicolumn{2}{|c|}{$\begin{array}{l}\text { Evaluation indexes } \\
\text { Expert remarks }\end{array}$} & Excellent & Well & Fair & Poor & Bad \\
\hline \multirow{4}{*}{$\begin{array}{c}\text { Corporate } \\
\text { economic } \\
\text { performance } B_{1}\end{array}$} & Enterprise economy scale $B_{11}$ & 2 & 6 & 16 & 5 & 1 \\
\hline & Cost of logistics recycling $B_{12}$ & 0 & 1 & 5 & 11 & 13 \\
\hline & Profitability $B_{13}$ & 1 & 1 & 9 & 12 & 7 \\
\hline & Ability to resist financial risk $B_{14}$ & 1 & 2 & 4 & 8 & 15 \\
\hline \multirow{4}{*}{$\begin{array}{l}\text { Social and } \\
\text { ecological } \\
\text { benefits } B_{2}\end{array}$} & Consumer awareness and participation degree $B_{21}$ & 0 & 6 & 5 & 15 & 4 \\
\hline & Government support intensity $B_{22}$ & 3 & 10 & 8 & 8 & 1 \\
\hline & Resources recycling capabilities $B_{23}$ & 10 & 9 & 7 & 3 & 1 \\
\hline & Environmental protection effect $B_{24}$ & 6 & 13 & 7 & 2 & 2 \\
\hline \multirow{3}{*}{$\begin{array}{c}\text { Eenterprise } \\
\text { technical } \\
\text { performance } B_{3}\end{array}$} & Specialization degree of recycling $B_{31}$ & 0 & 3 & 4 & 13 & 10 \\
\hline & Capability of product handling technology and equipment $B_{32}$ & 2 & 10 & 10 & 4 & 4 \\
\hline & Product types $B_{33}$ & 1 & 2 & 5 & 10 & 12 \\
\hline \multirow{3}{*}{$\begin{array}{c}\text { Business } \\
\text { development } \\
\text { strategies } B_{4}\end{array}$} & Business operation strategy $B_{41}$ & 3 & 9 & 12 & 4 & 2 \\
\hline & Recycling control ability $B_{42}$ & 10 & 12 & 4 & 3 & 1 \\
\hline & Secrecy degree of proprietary technology $B_{43}$ & 10 & 12 & 5 & 2 & 1 \\
\hline
\end{tabular}

Refer to the statistics in Table2, construct the fuzzy relation matrix $S^{1}=\left(S V_{1}^{1}, S V_{2}^{1}, S V_{3}^{1}, S V_{4}^{1}\right)^{T}$, that of $B$ relative to $V$, under manufacturer recycling model $O^{1}$. As there are $k=5$ kinds of expert remarks, and the number of evaluation index factor set $B_{1} 、 B_{2} 、 B_{3}$ and $B_{4}$, correspondingly, are $n_{1}=4, n_{2}=4$, $n_{3}=3, n_{4}=3$, obtain an expression for fuzzy relation matrix $s^{1}$ with expression (1) that can be described as:

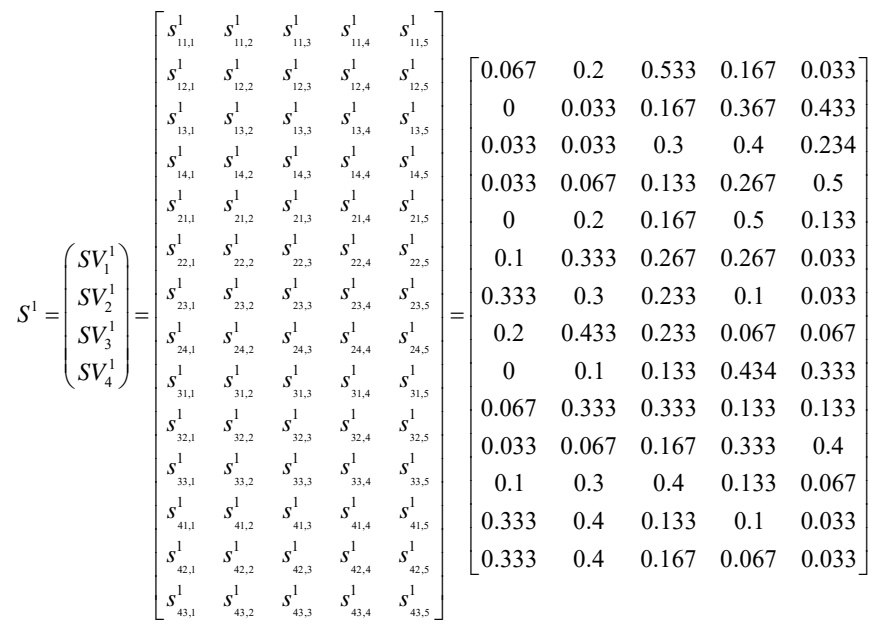

Repeat the above steps, obtain the fuzzy relation matrix $S^{2}$ and $S^{3}$ under dealers recycling and third-party enterprise recycling models respectively.

$$
\begin{aligned}
& S^{2}=\left(\begin{array}{l}
S V_{1}^{2} \\
S V_{2}^{2} \\
S V_{3}^{2} \\
S V_{4}^{2}
\end{array}\right)=\left[\begin{array}{ccccc}
0.233 & 0.333 & 0.267 & 0.133 & 0.033 \\
0.1 & 0.333 & 0.267 & 0.2 & 0.1 \\
0.133 & 0.367 & 0.233 & 0.167 & 0.1 \\
0.1 & 0.4 & 0.3 & 0.133 & 0.067 \\
0.067 & 0.167 & 0.433 & 0.267 & 0.067 \\
0.133 & 0.467 & 0.233 & 0.133 & 0.033 \\
0.2 & 0.433 & 0.3 & 0.1 & 0.067 \\
0.167 & 0.367 & 0.333 & 0.133 & 0.033 \\
0.2 & 0.3 & 0.333 & 0.133 & 0.333 \\
0.133 & 0.4 & 0.333 & 0.067 & 0.067 \\
0.033 & 0.1 & 0.233 & 0.367 & 0.267 \\
0.1 & 0.233 & 0.5 & 0.1 & 0.067 \\
0.267 & 0.333 & 0.3 & 0.067 & 0.033 \\
0.233 & 0.4 & 0.233 & 0.1 & 0.033
\end{array}\right] \\
& S^{3}=\left(\begin{array}{l}
S V_{1}^{3} \\
S V_{2}^{3} \\
S V_{3}^{3} \\
S V_{4}^{3}
\end{array}\right)=\left[\begin{array}{ccccc}
0.033 & 0.167 & 0.267 & 0.333 & 0.2 \\
0.333 & 0.367 & 0.167 & 0.1 & 0.033 \\
0.267 & 0.333 & 0.3 & 0.067 & 0.333 \\
0.5 & 0.3 & 0.167 & 0.033 & 0 \\
0.333 & 0.4 & 0.2 & 0.033 & 0.033 \\
0.2 & 0.433 & 0.233 & 0.067 & 0.067 \\
0.067 & 0.2 & 0.267 & 0.333 & 0.133 \\
0.033 & 0.2 & 0.033 & 0.233 & 0.2 \\
0.067 & 0.2 & 0.2 & 0.267 & 0.167 \\
0.233 & 0.467 & 0.167 & 0.067 & 0.067 \\
0.433 & 0.333 & 0.2 & 0.033 & 0 \\
0.067 & 0.2 & 0.467 & 0.2 & 0.067 \\
0.233 & 0.333 & 0.3 & 0.1 & 0.033 \\
0.1 & 0.267 & 0.333 & 0.167 & 0.133
\end{array}\right]
\end{aligned}
$$

Step5:To obtain the weight of each evaluation index $W$ with Fuzzy-Analytic Network Process FANP.

(1) Construct the weight super-matrix $\tilde{W}$ of second-level evaluation index 


\section{International Journal of Science and Research (IJSR) \\ ISSN (Online): 2319-7064}

Index Copernicus Value (2013): 6.14 | Impact Factor (2014): 5.611

$$
\tilde{W}=\left[\begin{array}{llll}
w_{11} & w_{12} & w_{13} & w_{14} \\
w_{21} & w_{22} & w_{23} & w_{24} \\
w_{31} & w_{32} & w_{33} & w_{34} \\
w_{41} & w_{42} & w_{43} & w_{44}
\end{array} \mid\right.
$$

Where the expression of sub-block $w_{i j}(i, j=1,2,3,4)$ is:

$$
\begin{gathered}
w_{i j}=\left[\begin{array}{llllll}
w^{(j 1)}, & w^{(j 2)}, & \ldots, & w^{(j q)}, & \ldots, & w^{\left(j n_{j}\right)}
\end{array}\right] \\
=\left[\begin{array}{cccccc}
w_{i 1}^{(j 1)} & w_{i 1}^{(j 2)} & \ldots & w_{i 1}^{(j q)} & \ldots & w_{i 1}^{\left(j n_{j}\right)} \\
w_{i 2}^{(j 1)} & w_{i 2}^{(j 2)} & \ldots & w_{i 2}^{(j q)} & \ldots & w_{i 2}^{\left(j n_{j}\right)} \\
\vdots & \vdots & \vdots & \vdots & \ldots & \vdots \\
w_{i p}^{(j 1)} & w_{i p}^{(j 2)} & \ldots & w_{i p}^{(j q)} & \ldots & w_{i p}^{\left(j n_{j}\right)} \\
\vdots & \vdots & \vdots & \vdots & \vdots & \vdots \\
w_{i n_{i}}^{(j 1)} & w_{i n_{i}}^{(j 2)} & \ldots & w_{i n_{i}}^{(j q)} & \ldots & w_{i n_{i}}^{\left(j n_{j}\right)}
\end{array}\right]
\end{gathered}
$$

For constructing the weight super-matrix $\tilde{W}$, the key is to define the column vector of sub-block $w_{i j}$, $w^{(j q)}=\left(w_{i 1}^{(j q)}, w_{i 2}^{(j q)}, \ldots, w_{i p}^{(j q)}, \ldots, w_{i i_{i}}^{(j q)}\right)^{T} \quad, \quad$ where $\quad p=1,2, \ldots, n_{i} \quad$, $q=1,2,3, \ldots, n_{j}$. Limited by the article length, we merely take the column vector of sub-block $w_{13}$, $w^{(31)}=\left(w_{11}^{(31)}, w_{12}^{(31)}, w_{13}^{(31)}, w_{14}^{(31)}\right)^{T}$, as an example(correspondingly, $i=1, j=3, n_{i}=n_{1}=4, n_{j}=n_{3}=3$ ) to show out its solving process, other column vectors of sub-block with the same solving process shall not be repeated.

In solving the column vector $w^{(31)}$, we select $H=3$ experienced experts of remanufacture product recycling to determine indirect dominance, triangular fuzzy number judgment matrix of the three experts could be expressed as $Z^{h}=\left(z_{e f}^{h}\right)_{4 \times 4}$, where $h=1,2,3, \quad e, f=1,2,3,4$.The specific solving process of column $w^{(31)}$ are as followings:

1) Denote indirect dominance of experts by triangular fuzzy numbers, construct judgment matrix $Z^{h}$ for experts evaluation triangular fuzzy numbers

The three triangular fuzzy numbers judgment matrix $Z^{1}$, $Z^{2}$ and $Z^{3}$ given out by 3 evaluation experts are shown from Table3-Table5.

Table 3: The indirect dominance judgment matrix $Z^{1}$ based on the criteria $B_{31}$

\begin{tabular}{|c|cccc|}
\hline$B_{31}$ & $B_{11}$ & $B_{12}$ & $B_{13}$ & $B_{14}$ \\
\hline$B_{11}$ & $(0.5,0.5,0.5)$ & $(0.6,0.7,0.8)$ & $(0.5,0.6,0.7)$ & $(0.7,0.8,0.9)$ \\
$B_{12}$ & $(0.2,0.3,0.4)$ & $(0.5,0.5,0.5)$ & $(0.3,0.4,0.5)$ & $(0.3,0.4,0.5)$ \\
$B_{13}$ & $(0.3,0.4,0.5)$ & $(0.5,0.6,0.7)$ & $(0.5,0.5,0.5)$ & $(0.5,0.5,0.5)$ \\
$B_{14}$ & $(0.1,0.2,0.3)$ & $(0.5,0.6,0.7)$ & $(0.5,0.5,0.5)$ & $(0.5,0.5,0.5)$ \\
\hline
\end{tabular}

Table 4: The indirect dominance judgment matrix $Z^{2}$ based on the criteria $B_{31}$

\begin{tabular}{|c|cccc|}
\hline$B_{31}$ & $B_{11}$ & $B_{12}$ & $B_{13}$ & $B_{14}$ \\
\hline$B_{11}$ & $(0.5,0.5,0.5)$ & $(0.5,0.6,0.7)$ & $(0.6,0.7,0.8)$ & $(0.6,0.7,0.8)$ \\
$B_{12}$ & $(0.3,0.4,0.5)$ & $(0.5,0.5,0.5)$ & $(0.4,0.5,0.6)$ & $(0.2,0.3,0.4)$ \\
$B_{13}$ & $(0.2,0.3,0.4)$ & $(0.4,0.5,0.6)$ & $(0.5,0.5,0.5)$ & $(0.4,0.5,0.6)$ \\
$B_{14}$ & $(0.2,0.3,0.4)$ & $(0.6,0.7,0.8)$ & $(0.4,0.5,0.6)$ & $(0.5,0.5,0.5)$ \\
\hline
\end{tabular}

Table 5: The indirect dominance judgment matrix $Z^{3}$ based on the criteria $B_{31}$

\begin{tabular}{|c|cccc|}
\hline$B_{31}$ & $B_{11}$ & $B_{12}$ & $B_{13}$ & $B_{14}$ \\
\hline$B_{11}$ & $(0.5,0.5,0.5)$ & $(0.7,0.7,0.8)$ & $(0.4,0.5,0.6)$ & $(0.7,0.8,0.8)$ \\
$B_{12}$ & $(0.2,0.3,0.3)$ & $(0.5,0.5,0.5)$ & $(0.3,0.4,0.4)$ & $(0.4,0.4,0.5)$ \\
$B_{13}$ & $(0.4,0.5,0.6)$ & $(0.6,0.6,0.7)$ & $(0.5,0.5,0.5)$ & $(0.5,0.6,0.6)$ \\
$B_{14}$ & $(0.2,0.2,0.3)$ & $(0.5,0.6,0.6)$ & $(0.4,0.4,0.5)$ & $(0.5,0.5,0.5)$ \\
\hline
\end{tabular}

2) Mass triangular fuzzy numbers judgment matrixes $Z^{1}$, $Z^{2}$ and $Z^{3}$ to form a single judgment matrix $Z$, calculate the fuzzy comprehensive evaluation value $a_{e}$ of second-level evaluation indexes.

Use formula (4) to mass the preference information of three triangular fuzzy number judgment matrix, constitute a single triangular fuzzy number judgment matrix $Z$

$$
Z=\left[\begin{array}{cccc}
(0.5,0.5,0.5) & (0.6,0.67,0.77) & (0.5,0.6,0.7) & (0.67,0.77,0.8) \\
(0.23,0.33,0.4) & (0.5,0.5,0.5) & (0.33,0.4,0.5) & (0.3,0.37,0.5) \\
(0.3,0.4,0.5) & (0.5,0.57,0.67) & (0.5,0.5,0.5) & (0.47,0.53,0.6) \\
(0.17,0.23,0.3) & (0.53,0.63,0.7) & (0.43,0.5,0.5) & (0.5,0.5,0.5)
\end{array}\right]
$$

Apply formula (5) to calculate the fuzzy comprehensive evaluation value $a_{e}$ of each second-level evaluation index,

$e=1,2,3,4$.

$$
\begin{array}{cc}
a_{1}=(0.25,0.32,0.4), & a_{2}=(0.15,0.2,0.27) \\
a_{3}=(0.19,0.25,0.32), & a_{4}=(0.38,0.23,0.28)
\end{array}
$$

3) Compute the expectation $E\left(a_{e}\right)$ for fuzzy comprehensive evaluation value $a_{e}$ and acquire the sorted vector of impact $w^{31}$ through normalization process.

On Considering that the expert evaluation is neutral, the optimism-pessimism factor is set as $\eta=1 / 2$.Use formula (6) to calculate the expectation of fuzzy comprehensive evaluation value $a_{e}$ that of each second-level evaluation index $E\left(a_{e}\right)=\left(l_{e}+2 m_{e}+u_{e}\right) / 4, e=1,2,3,4$.

$$
E\left(a_{1}\right)=\left(l_{1}+2 m_{1}+u_{1}\right) / 4=(0.25+2 \times 0.32+0.4) / 4=0.32
$$

Similarly, calculate the other expectations $E\left(a_{2}\right)=0.21$, $E\left(a_{3}\right)=0.25, \quad E\left(a_{4}\right)=0.23$.

Use formula (8) to compute each element of influence degree sort column vector $w^{(31)}, w_{11}^{(31)}, w_{12}^{(31)}, w_{13}^{(31)}, w_{14}^{(31)}$, where:

$$
\begin{gathered}
w_{11}^{(31)}=\frac{E\left(a_{1}\right)}{\sum_{e=1}^{4} E\left(a_{e}\right)}=0.32 w_{12}^{(31)}=\frac{E\left(a_{2}\right)}{\sum_{e=1}^{4} E\left(a_{e}\right)}=0.20 \\
w_{13}^{(31)}=\frac{E\left(a_{3}\right)}{\sum_{e=1}^{4} E\left(a_{e}\right)}=0.25 w_{14}^{(31)}=\frac{E\left(a_{4}\right)}{\sum_{e=1}^{4} E\left(a_{e}\right)}=0.23
\end{gathered}
$$




\section{International Journal of Science and Research (IJSR) \\ ISSN (Online): 2319-7064}

Index Copernicus Value (2013): 6.14 | Impact Factor (2014): 5.611

Therefore, $w^{(31)}=\left(w_{11}^{(31)}, w_{12}^{(31)}, w_{13}^{(31)}, w_{14}^{(31)}\right)^{T}=(0.32,0.20,0.25,0.23)^{T}$.

Repeat the process above, obtain the other two vectors of bub-blocks $w^{13}, w^{(32)}$ and $w^{(33)}$, where:

$$
\begin{aligned}
& w^{(32)}=\left(w_{11}^{(32)}, w_{12}^{(32)}, w_{13}^{(32)}, w_{14}^{(32)}\right)^{T}=(0.238,0.545,0.118,0.099)^{T} \\
& w^{(33)}=\left(w_{11}^{(33)}, w_{12}^{(33)}, w_{13}^{(33)}, w_{14}^{(33)}\right)^{T}=(0.557,0.176,0.165,0.102)^{T}
\end{aligned}
$$

Therefore, the matrix expression of sub-block $w^{13}$ is:

$$
w_{13}=\left[w^{(31)}, w^{(32)}, w^{(33)}\right]=\left[\begin{array}{lll}
0.32 & 0.238 & 0.557 \\
0.20 & 0.545 & 0.176 \\
0.25 & 0.118 & 0.165 \\
0.23 & 0.099 & 0.102
\end{array}\right]
$$

With the above steps, the matrix expression the other sub-blocks can be calculated as:

$$
\begin{aligned}
& w_{11}=\left[\begin{array}{cccc}
0.146 & 0.214 & 0.1 & 0.172 \\
0.076 & 0.121 & 0.411 & 0.122 \\
0.474 & 0.514 & 0.29 & 0.303 \\
0.304 & 0.151 & 0.199 & 0.403
\end{array}\right] \\
& w_{12}=\left[\begin{array}{cccc}
0.495 & 0.399 & 0.487 & 0.228 \\
0.225 & 0.133 & 0.187 & 0.335 \\
0.19 & 0.194 & 0.182 & 0.218 \\
0.09 & 0.274 & 0.144 & 0.199
\end{array}\right] \\
& w_{13}=\left[\begin{array}{ccc}
0.32 & 0.238 & 0.557 \\
0.20 & 0.545 & 0.176 \\
0.25 & 0.118 & 0.165 \\
0.23 & 0.099 & 0.102
\end{array}\right] \quad w_{14}=\left[\begin{array}{ccc}
0.479 & 0.625 & 0.5 \\
0.116 & 0.125 & 0.167 \\
0.165 & 0.125 & 0.166 \\
0.24 & 0.125 & 0.167
\end{array}\right] \\
& w_{21}=\left[\begin{array}{cccc}
0.143 & 0.135 & 0.087 & 0.256 \\
0.47 & 0.431 & 0.165 & 0.123 \\
0.244 & 0.327 & 0.546 & 0.108 \\
0.143 & 0.107 & 0.202 & 0.513
\end{array}\right] \\
& w_{22}=\left[\begin{array}{cccc}
0.112 & 0.334 & 0.487 & 0.465 \\
0.372 & 0.433 & 0.465 & 0.119 \\
0.257 & 0.13 & 0.266 & 0.124 \\
0.259 & 0.103 & 0.11 & 0.292
\end{array}\right] \\
& w_{23}=\left[\begin{array}{ccc}
0.091 & 0.135 & 0.104 \\
0.171 & 0.3 & 0.214 \\
0.406 & 0.461 & 0.281 \\
0.332 & 0.104 & 0.401
\end{array}\right] \quad w_{24}=\left[\begin{array}{ccc}
0.103 & 0.136 & 0.132 \\
0.421 & 0.501 & 0.478 \\
0.275 & 0.19 & 0.195 \\
0.201 & 0.173 & 0.195
\end{array}\right] \\
& w_{31}=\left[\begin{array}{cccc}
0.259 & 0.147 & 0.132 & 0.1 \\
0.601 & 0.565 & 0.614 & 0.494 \\
0.14 & 0.288 & 0.254 & 0.406
\end{array}\right] \\
& w_{32}=\left[\begin{array}{cccc}
0.205 & 0.436 & 0.245 & 0.205 \\
0.217 & 0.41 & 0.643 & 0.731 \\
0.578 & 0.154 & 0.112 & 0.064
\end{array}\right]
\end{aligned}
$$

$W=\lim _{k \rightarrow \infty}(\bar{W})^{k}=(0.093,0.058,0.058,0.043,0.086,0.144,0.101,0.079,0.043,0.086,0.029,0.058,0.079,0.043)$

$$
\begin{aligned}
& w_{33}=\left[\begin{array}{ccc}
0.171 & 0.279 & 0.1 \\
0.74 & 0.646 & 0.528 \\
0.089 & 0.075 & 0.372
\end{array}\right] w_{34}=\left[\begin{array}{ccc}
0.313 & 0.649 & 0.156 \\
0.201 & 0.203 & 0.327 \\
0.486 & 0.148 & 0.517
\end{array}\right] \\
& w_{41}=\left[\begin{array}{cccc}
0.688 & 0.63 & 0.254 & 0.206 \\
0.183 & 0.218 & 0.614 & 0.685 \\
0.129 & 0.152 & 0.132 & 0.109
\end{array}\right] \\
& w_{42}=\left[\begin{array}{llll}
0.524 & 0.486 & 0.643 & 0.592 \\
0.279 & 0.313 & 0.214 & 0.242 \\
0.197 & 0.201 & 0.143 & 0.166
\end{array}\right] \\
& w_{43}=\left[\begin{array}{lll}
0.201 & 0.201 & 0.147 \\
0.313 & 0.313 & 0.233 \\
0.486 & 0.486 & 0.620
\end{array}\right] \quad w_{44}=\left[\begin{array}{lll}
0.271 & 0.178 & 0.156 \\
0.608 & 0.575 & 0.327 \\
0.121 & 0.247 & 0.517
\end{array}\right]
\end{aligned}
$$

Therefore, the weight super-matrix $\tilde{W}$ of second-level evaluation index can be obtained as shown in formula (11).

(2) Construct fuzzy weight matrix $A$ for first-level evaluation index factor set. Use the same way defining weight matrix for second-level evaluation index to construct matrix A.

$$
A=\left[\begin{array}{llll}
a_{11} & a_{12} & a_{13} & a_{14} \\
a_{21} & a_{22} & a_{23} & a_{24} \\
a_{31} & a_{32} & a_{33} & a_{34} \\
a_{41} & a_{42} & a_{43} & a_{44}
\end{array}\right]=\left[\begin{array}{cccc}
0.25 & 0.224 & 0.33 & 0.283 \\
0.533 & 0.566 & 0.128 & 0.105 \\
0.109 & 0.105 & 0.461 & 0.081 \\
0.108 & 0.105 & 0.081 & 0.531
\end{array}\right]
$$

(3) Construct fuzzy weighted super-matrix $\bar{W}$, compute its limit stable vectors $W$ as the weight of each second-level evaluation index

Use formula (10)to compute fuzzy weighted super-matrix $\bar{W}$ :

$$
\bar{W}=A \bullet \tilde{W}=\left|\begin{array}{llll}
a_{11} w_{11} & a_{12} w_{12} & a_{13} w_{13} & a_{14} w_{14} \\
a_{21} w_{21} & a_{22} w_{22} & a_{23} w_{23} & a_{24} w_{24} \\
a_{31} w_{31} & a_{32} w_{32} & a_{33} w_{33} & a_{34} w_{34} \\
a_{41} w_{41} & a_{42} w_{42} & a_{43} w_{43} & a_{44} w_{44}
\end{array}\right|
$$

The computing result of fuzzy weighted super-matrix $\bar{W}$ is shown in formula (12).Compute the limit stable vectors of fuzzy weighted super-matrix $\bar{W}$ as the weight of second-level evaluation index $W$.

$$
\tilde{W}=\left[\begin{array}{cccccccccccccc}
0.146 & 0.214 & 0.1 & 0.172 & 0.495 & 0.399 & 0.487 & 0.228 & 0.32 & 0.238 & 0.557 & 0.479 & 0.625 & 0.5 \\
0.076 & 0.121 & 0.411 & 0.122 & 0.225 & 0.133 & 0.187 & 0.335 & 0.20 & 0.545 & 0.176 & 0.116 & 0.125 & 0.167 \\
0.474 & 0.514 & 0.29 & 0.303 & 0.19 & 0.194 & 0.182 & 0.218 & 0.25 & 0.118 & 0.165 & 0.165 & 0.125 & 0.166 \\
0.304 & 0.151 & 0.199 & 0.403 & 0.09 & 0.274 & 0.144 & 0.199 & 0.23 & 0.099 & 0.102 & 0.24 & 0.125 & 0.167 \\
0.143 & 0.135 & 0.087 & 0.256 & 0.112 & 0.334 & 0.487 & 0.465 & 0.091 & 0.135 & 0.104 & 0.103 & 0.136 & 0.132 \\
0.47 & 0.431 & 0.165 & 0.123 & 0.372 & 0.433 & 0.465 & 0.119 & 0.171 & 0.3 & 0.214 & 0.421 & 0.501 & 0.478 \\
0.244 & 0.327 & 0.546 & 0.108 & 0.257 & 0.13 & 0.266 & 0.124 & 0.406 & 0.461 & 0.281 & 0.275 & 0.19 & 0.195 \\
0.143 & 0.107 & 0.202 & 0.513 & 0.259 & 0.103 & 0.11 & 0.292 & 0.332 & 0.104 & 0.401 & 0.201 & 0.173 & 0.195 \\
0.259 & 0.147 & 0.132 & 0.1 & 0.205 & 0.436 & 0.245 & 0.205 & 0.171 & 0.279 & 0.1 & 0.313 & 0.649 & 0.156 \\
0.601 & 0.565 & 0.614 & 0.494 & 0.217 & 0.41 & 0.643 & 0.731 & 0.74 & 0.646 & 0.528 & 0.201 & 0.203 & 0.327 \\
0.14 & 0.288 & 0.254 & 0.406 & 0.578 & 0.154 & 0.112 & 0.064 & 0.089 & 0.075 & 0.372 & 0.486 & 0.148 & 0.517 \\
0.688 & 0.63 & 0.254 & 0.206 & 0.524 & 0.486 & 0.643 & 0.592 & 0.201 & 0.201 & 0.147 & 0.271 & 0.178 & 0.156 \\
0.183 & 0.218 & 0.614 & 0.685 & 0.279 & 0.313 & 0.214 & 0.242 & 0.313 & 0.313 & 0.233 & 0.608 & 0.575 & 0.327 \\
0.129 & 0.152 & 0.132 & 0.109 & 0.197 & 0.201 & 0.143 & 0.166 & 0.486 & 0.486 & 0.620 & 0.121 & 0.247 & 0.517
\end{array}\right]
$$




\section{International Journal of Science and Research (IJSR) \\ ISSN (Online): 2319-7064}

Index Copernicus Value (2013): 6.14 | Impact Factor (2014): 5.611

$\bar{W}=\left[\begin{array}{cccccccccccccc}0.037 & 0.054 & 0.025 & 0.043 & 0.111 & 0.09 & 0.110 & 0.051 & 0.170 & 0.078 & 0.184 & 0.136 & 0.177 & 0.141 \\ 0.019 & 0.030 & 0.103 & 0.030 & 0.05 & 0.03 & 0.042 & 0.08 & 0.072 & 0.180 & 0.058 & 0.033 & 0.035 & 0.047 \\ 0.118 & 0.129 & 0.073 & 0.076 & 0.043 & 0.430 & 0.041 & 0.049 & 0.046 & 0.039 & 0.054 & 0.046 & 0.035 & 0.047 \\ 0.076 & 0.038 & 0.049 & 0.101 & 0.021 & 0.062 & 0.032 & 0.045 & 0.042 & 0.033 & 0.034 & 0.068 & 0.035 & 0.047 \\ 0.076 & 0.072 & 0.046 & 0.136 & 0.063 & 0.189 & 0.09 & 0.263 & 0.012 & 0.017 & 0.013 & 0.011 & 0.014 & 0.014 \\ 0.250 & 0.229 & 0.088 & 0.066 & 0.210 & 0.246 & 0.263 & 0.067 & 0.022 & 0.038 & 0.027 & 0.044 & 0.053 & 0.05 \\ 0.130 & 0.174 & 0.290 & 0.057 & 0.145 & 0.073 & 0.151 & 0.070 & 0.052 & 0.059 & 0.036 & 0.029 & 0.02 & 0.02 \\ 0.076 & 0.056 & 0.108 & 0.273 & 0.147 & 0.058 & 0.062 & 0.165 & 0.043 & 0.013 & 0.051 & 0.021 & 0.018 & 0.020 \\ 0.028 & 0.016 & 0.014 & 0.011 & 0.021 & 0.046 & 0.026 & 0.021 & 0.079 & 0.128 & 0.046 & 0.025 & 0.053 & 0.013 \\ 0.065 & 0.061 & 0.067 & 0.054 & 0.023 & 0.043 & 0.067 & 0.077 & 0.341 & 0.298 & 0.243 & 0.016 & 0.016 & 0.027 \\ 0.015 & 0.031 & 0.028 & 0.044 & 0.061 & 0.016 & 0.012 & 0.007 & 0.041 & 0.035 & 0.172 & 0.039 & 0.012 & 0.042 \\ 0.075 & 0.068 & 0.028 & 0.022 & 0.055 & 0.051 & 0.067 & 0.062 & 0.016 & 0.016 & 0.012 & 0.144 & 0.094 & 0.083 \\ 0.020 & 0.024 & 0.067 & 0.074 & 0.029 & 0.033 & 0.022 & 0.025 & 0.025 & 0.025 & 0.019 & 0.323 & 0.305 & 0.174 \\ 0.014 & 0.016 & 0.014 & 0.012 & 0.021 & 0.021 & 0.015 & 0.017 & 0.039 & 0.039 & 0.05 & 0.064 & 0.132 & 0.275\end{array}\right]$

Step6: Apply fuzzy comprehensive evaluation model $M(\bullet,+)$ to calculate the final evaluation scores of three types of end-of-life electromechanical product take-back models, $T=\left(T^{1}, T^{2}, T^{3}\right)$.

The final score of remanufacture recycling model $T^{1}=W \bullet S^{1} \bullet R^{T}$, the calculation process is:

$$
T^{1}=\left[\begin{array}{c}
0.093 \\
0.058 \\
0.058 \\
0.043 \\
0.086 \\
0.144 \\
0.101 \\
0.079 \\
0.043 \\
0.086 \\
0.029 \\
0.058 \\
0.079 \\
0.043
\end{array}\right] \bullet\left[\begin{array}{ccccc}
0.067 & 0.2 & 0.533 & 0.167 & 0.033 \\
0 & 0.033 & 0.167 & 0.367 & 0.433 \\
0.033 & 0.033 & 0.3 & 0.4 & 0.234 \\
0.033 & 0.067 & 0.133 & 0.267 & 0.5 \\
0 & 0.2 & 0.167 & 0.5 & 0.133 \\
0.1 & 0.333 & 0.267 & 0.267 & 0.033 \\
0.333 & 0.3 & 0.233 & 0.1 & 0.033 \\
0.2 & 0.433 & 0.233 & 0.067 & 0.067 \\
0 & 0.1 & 0.133 & 0.434 & 0.333 \\
0.067 & 0.333 & 0.333 & 0.133 & 0.133 \\
0.033 & 0.067 & 0.167 & 0.333 & 0.4 \\
0.1 & 0.3 & 0.4 & 0.133 & 0.067 \\
0.333 & 0.4 & 0.133 & 0.1 & 0.033 \\
0.333 & 0.4 & 0.167 & 0.067 & 0.033
\end{array}\right] \bullet\left[\begin{array}{c}
100 \\
80 \\
60 \\
40 \\
20
\end{array}\right]=61.32
$$

Repeat the process above, obtain the final evaluation scores $T^{2}$ and $T^{3}$ for dealers recycling model and third-party enterprise recycling model correspondingly.

$$
\begin{aligned}
& T^{2}=W \bullet S^{2} \bullet R^{T}=68.04 \\
& T^{3}=W \bullet S^{3} \bullet R^{T}=67.05
\end{aligned}
$$

Step7: The final evaluation scores of 3 types of waste electromechanical product take-back models $T=\left(T^{1}, T^{2}, T^{3}\right)=(61.32,68.06,67.05)$. Since the final score of dealer recycling model is quite close to the third-party enterprise recycling model, both of them shall be chose as the best take-back model for waste electromechanical products.

\subsection{Result Analysis}

Gather the scores of each evaluation index of three kinds of take-back models as shown in Table 6, compare and analyze the table to obtain the following conclusion:

(1) The results are consistent with realistic choice of enterprises, proving the model efficient
By comparing the final evaluation scores of three kinds of take-back models, we could get to know, that in relevant to the manufacturer recycling model, the scores of dealer recycling model and third-part enterprise recycling model are closer and higher, demonstrating that they are two better bake-back models(however, their scores are till relatively low). In real life, as the remanufacturing industry is still in its infancy, remanufacturing enterprises have a small scale on average, and the consumer acceptance is also on the low side, distributors and third-party companies tend to take advantage of their existing distribution network to realize waste products recycling, which can effectively reduce the cost and enhance the level of recycling service, therefore, these two kinds of models are adopted in most automobile engine recycling. This, to a certain extent, confirm the validity of the model in this paper.

(2) Aggrandize advantaged evaluation index, focus on disadvantaged evaluation index, achieve the diversification of recycling model selection

According to this paper, from the perspective of evaluation factor set : in the two aspects of enterprise economic efficiency and technical efficiency, dealers and the third-party recycling models have obvious advantages; In terms of social and ecological benefits, three kinds of recycling models scores no much difference; In the aspect of enterprise development strategy, remanufacturers recycling model prominent narrowly. This explains the lower score of remanufacturers recycling model in final evaluation.

From the perspective of second-level evaluation indexes: compared to other two products recycling models, remanufactures recycling model slightly occupy the dominant position in terms of resource recycling, environmental protection effect, recycling control ability, product processing technology and equipment level, the degree of secrecy for products proprietary technology, and a few other second-level evaluation indexes. Whereas, the model is in a vulnerable position when it comes to logistics recycling ability, profit ability, financial risks resisting ability, consumer cognition and participation degree, specialization degree of recycling, product types and majority of the evaluation indexes. 


\section{International Journal of Science and Research (IJSR) \\ ISSN (Online): 2319-7064}

Index Copernicus Value (2013): 6.14 | Impact Factor (2014): 5.611

Table 6: Scoring statistics of each second-level evaluation index of three kinds of take-back models

\begin{tabular}{|c|c|c|c|c|}
\hline \multicolumn{2}{|l|}{ Evaluation indexes } & \begin{tabular}{|c|}
$\begin{array}{c}\text { Manufacturer } \\
\text { recycling model }\end{array}$ \\
Values \\
\end{tabular} & $\begin{array}{c}\begin{array}{c}\text { Dealer } \\
\text { recycling } \\
\text { model }\end{array} \\
\text { Values } \\
\end{array}$ & $\begin{array}{c}\begin{array}{c}\text { Third-party } \\
\text { enterprise } \\
\text { recycling model }\end{array} \\
\text { Values }\end{array}$ \\
\hline \multirow{5}{*}{$\begin{array}{l}\text { Corporate economic } \\
\text { performancese }\end{array}$} & Enterprise economy scale & 5.77 & 6.7 & 4.65 \\
\hline & Cost of logistics recycling & 2.09 & 3.64 & 4.48 \\
\hline & Profitability & 2.59 & 3.79 & 4.33 \\
\hline & Ability to resist financial risk & 1.6 & 2.89 & 3.67 \\
\hline & Total score of index set & 12.05 & 17.02 & 17.13 \\
\hline \multirow{5}{*}{$\begin{array}{c}\text { Social and ecological } \\
\text { benefits }\end{array}$} & Consumer awareness and participation degree & 4.19 & 4.99 & 6.82 \\
\hline & Government support intensity & 9.22 & 10.18 & 10.47 \\
\hline & Resources recycling capabilities & 7.68 & 7.27 & 5.52 \\
\hline & Environmental protection effect & 5.74 & 5.53 & 4.16 \\
\hline & Total score of index set & 26.83 & 27.97 & 26.97 \\
\hline \multirow{4}{*}{$\begin{array}{l}\text { Eenterprise technical } \\
\text { performance }\end{array}$} & Specialization degree of recycling & 1.72 & 3.01 & 2.27 \\
\hline & Ccapability of product handling technology and equipment & 6.27 & 5.96 & 6.43 \\
\hline & Product types & 1.16 & 1.31 & 2.42 \\
\hline & Total score of index set & 9.15 & 10.28 & 11.12 \\
\hline \multirow{4}{*}{$\begin{array}{l}\text { Business development } \\
\text { strategies }\end{array}$} & Business operation strategy & 3.75 & 3.71 & 3.48 \\
\hline & Recycling control ability & 6.16 & 5.9 & 5.74 \\
\hline & Secrecy degree of proprietary technology & 3.38 & 3.18 & 2.61 \\
\hline & Total score of index set & 13.29 & 12.79 & 11.83 \\
\hline & Final evaluation score & 61.32 & 68.06 & 67.05 \\
\hline
\end{tabular}

For remanufacturing enterprises, the ideal external developing environment is for the three kinds of recycling models to realize a further and balanced development, that is, the final evaluation scores of the models should be higher and close to each other, in this way, enterprises do not have to take unnecessary time and effort in selection recycling model. In order to achieve the above developing goals, we should adopt the following countermeasures:

1) Remanufactures recycling model should focus on the construction of disadvantaged evaluation indexes Considering the current development situation of domestic remanufacturing industry, the recycling model should focus on strengthening the recycling infrastructure and the construction of the network, so as to effectively improve consumer cognition and participation, logistics capability evaluation indexes, etc. At the same time, reduce logistic costs to improve the indexes of profitability and ability to resist financial risks, thus achieve an effective promotion of final evaluation score of remanufacturers recycling model overall.

2) Dealers recycling and third-party enterprises recycling models should maintain advantaged evaluation indexes, and further improve the disadvantaged evaluation indexes. At present, only remanufacturers have the processing technology and ability for the whole recycling process, so the above two kinds of recycling models are relatively weak in control ability of recycling product, processing capacity and resources recycling ability. To improve this situation, the dealer and third-party enterprises should keep existing advantaged evaluation indexes, and consider to further strengthen the strategic partnership with remanufactures, strive to get part of the remanufacture processing technology and process from remanufactures, such as moving forward dismantling or testing links that are originally performed by the manufacturer, so as to effectively improve the disadvantaged evaluation indexes of this two models, and further enhance their final evaluation scores.

\section{Conclusion}

The choice of take-back models for End-of-Life electromechanical products involves in many types of evaluation indexes, which have a network relation of mutual dependence and feedback. In addition, there is a strong fuzziness while experts judging the relative importance of different indices. This article designed an evaluation index system that completely reflects the internal network relations of indexes, for selection of take-back models of waste electromechanical products. On this basis, the Fuzzy Analytic Network Process model was established, adopting the fuzzy comprehensive evaluation to overcome the fuzziness of expert evaluation, using the Analytic Network Process method to analyze the network structure relation of evaluation indexes. It can help the remanufacturers solve the choice of take-back models for used electromechanical products. At the same time, the research analyzed the selection result of the recycling models and puts forward the corresponding countermeasures for enterprises.

\section{Acknowledgment}

This work is supported in part by National Natural Science Foundation of China (No.71273131), Humanity \& Social Science Foundation of Ministry of Education of China (NO.10YJC630157), Key Project of Philosophy and Social Science Research in Colleges and Universities in Jiangsu Province of China (NO: 2011ZDIXM052), the Fundamental Research Funds for the Central Universities (NR2012009), China Postdoctoral Science Foundation (No.2010048114),

\section{References}

[1] A.J.Spicer, MR.Johnson. Third party Remanufacturing as a Solution for Extended Producer Responsibility

[2] Journal of Cleaner Production, 2004, 12:37-45.

[3] Xu Z R, Guo Y X. Study on Take-back Models for 


\section{International Journal of Science and Research (IJSR) \\ ISSN (Online): 2319-7064}

Index Copernicus Value (2013): 6.14 | Impact Factor (2014): 5.611

Extended Producer Responsibility [J]. Economic Management, 2005, 10:65-70.

[4] Luo W. Comparison and Choice on Recycling Mode Performed by EPR [J]. Business Economy, 2009, 9:62-66.

[5] Zhang H, Da Q L. Analyzing the model selection for remanufacturing logistics network from strategic views [J]. Modern Management Science, 2007, 9:28-38.

[6] Yan X X, Jin J. Analys is of End-of-Life product callback model based on reverse logistics [J]. Storage, Transportation \& Preservation of Commodities, 2008, 30(2):48-50.

[7] Kannan Govindan, Murugesan Palaniappan, Qinghua Zhu, Devika Kannan. Analysis of third party reverse logistics provider using interpretive structural modeling[J]. Omega, 2002, (30):66-67.

[8] Savaskan R.C, Bhattacharya W, LN.Van Wassenhove. Closed-loop supply chain models with product remanufacturing [J].Management Science, 2004, 50(2):239-252.

[9] Yao W X. Comparison of Different Take- Back Models in Reverse Logistics [J]. Management Science in China, 2004, 2:76-79.

[10] Wei J, Li J. The Choice of Different Take- Back Models in Reverse Logistics with the Restriction of EPR [J]. Chinese Journal of Management Science, 2005, 13(6):18-22.

[11] Wang X, Liang G Q. Analysis of reclaiming models of used products based on remanufacturing reverse logistics[J]. Modern Manufacturing Engineering, 2009, 4:9-11.

[12] Gong Y D, Li B Y. Integration Research on Critical Conditions of Logistics Outsourcing and Recovery Strategy for Three-stage CLSC [J]. Journal of Industrial Engineering and Engineering, 2010, 2:124-129.

[13]Ren M M. Tong H L. C. Choice the Take-Back Models of EPR Based on Fuzzy Comprehensive Evaluation [J]. Statistics and Decision, 2009, 15: 42-44.

[14] Jiang Y L. Fan Z P.]. A Ranking Method for Reciprocal Judgment Matrix With Triangular Fuzzy Numbers [J]. Systems Engineering and Electronics n, 2002, 24(7):34-36.

[15] Liou TS, Wang M J • Ranking Fuzzy Numbers with Integral Value [J]. Fuzzy Sets and System, 1992, 50:247-255.

[16]Kaufman A, Gupta MM. Introduction to Fuzzy Arithmetic: Theory and Applications [M]. NewYork: Van Nostrand Reinhold, 1985, 141-149. 